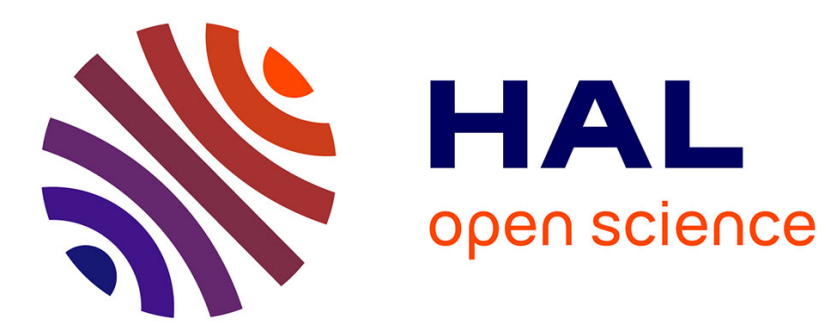

\title{
ELECTRICAL PROPERTIES AND MICROSTRUCTURE OF INTERNAL INTERFACES IN Al DOPED POLYSILICON
}

J. Maurice, J. Laval, J. Bouree

\section{- To cite this version:}

J. Maurice, J. Laval, J. Bouree. ELECTRICAL PROPERTIES AND MICROSTRUCTURE OF INTERNAL INTERFACES IN Al DOPED POLYSILICON. Journal de Physique Colloques, 1985, 46 (C4), pp.C4-405-C4-410. 10.1051/jphyscol:1985443 . jpa-00224694

\section{HAL Id: jpa-00224694 https://hal.science/jpa-00224694}

Submitted on 1 Jan 1985

HAL is a multi-disciplinary open access archive for the deposit and dissemination of scientific research documents, whether they are published or not. The documents may come from teaching and research institutions in France or abroad, or from public or private research centers.
L'archive ouverte pluridisciplinaire HAL, est destinée au dépôt et à la diffusion de documents scientifiques de niveau recherche, publiés ou non, émanant des établissements d'enseignement et de recherche français ou étrangers, des laboratoires publics ou privés. 


\author{
J.L. Maurice, J.Y. Laval and J.E. Bouree ${ }^{+}$ \\ Laboratoire de Chimie et Microstructure du Solide Minéral*, CNRS-ESPCI, \\ 10, rue Vauquelin, 75231 Paris Cedex 05, France

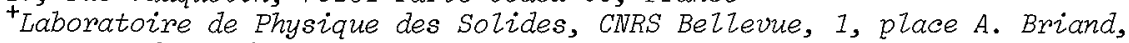 \\ 92195 Meudon Cedex, France
}

Résumé : Les propriētés électriques du silicium polycristallin varient fortement avec la concentration en aluminium $\left(\mathrm{N}_{\mathrm{A}}\right)$. En effet, cet élément peut jouer le rôle non seulement d'accepteur ou de centre de recombinaison intragranulairemais encore de passivant électrique aux joints de grains suivant le site qu'il occupe ou son environnement chimique. L'influence de l'oxygène sur le phënomène de précipitation aux interfaces internes et aux dislocations est analysée. Par ailleurs, la cartographie LBIC permet de caractêriser l'activi té électrique des joints de grains et en particulier des macles en relation avec le mécanisme de coségrégation.

Abstract : In polysilicon, electrical properties are strongly influenced by AT concentration ( $\mathrm{N}_{\mathrm{Al}}$ ). Al acts as an acceptor or as a recombinating agent within grains and it can electrically passivate grain boundaries, according to $i$ ts site occupation or to its chemical environment. The influence of oxygen on the Al precipitation at internal interfaces and dislocations was analysed. The LBIC technique was applied in the mapping mode to characterize the electrical activity of grain boundaries and specifically of twin boundaries in relationship with co-segregation mechantsm.

\title{
1 - INTRODUCTION
}

In polysilicon, aluminium is a noticeable dopant since it can act as an acceptor or as a trap for electrons (respective energy levels : $0.06 \mathrm{eV}$ and $0.43 \mathrm{eV}$ above the valence band edge $/ 1 /$ ) and it can also passivate grain boundaries $/ 2 /$. Additionally, Al interacts with oxygen $/ 3,4 /$ and $i$ ts electrical activity will depend on the heat treatments $/ 2,3 /$.

This work is part of an extensive investigation on the impurity-defect interaction in poly-Si and its influence on electrical properties. The p-type poly-Si was prepared by the Heat Exchanger Method * $/ 5 /$ with an $A 1$ concentration ( $N_{A 1}$ ) ranging from $1.610^{17}$ at $\mathrm{cm}^{-3}$ to $10^{20}$ at $\mathrm{cm}^{-3}$. In a preliminary work $/ 6 /$, we have shown that the acceptor concentration to $\left.N_{A}\right]$ ratio diminishes when $N_{A}$ increases. Moreover, the aluminium atoms which do not enter into acceptor sites will be found in at least two types of sites : bulk trap sites and specific sites at grain boundaries.

Analytical electron microscopy showed Al segregation at grain boundaries for $N_{A 1} \simeq 10^{19}$ at cm${ }^{-3}$, i.e. below the solubility limit. At $N_{A 1}=10^{20}$ at $\mathrm{cm}^{-3}$, a decrease in intragrain defect density is observed in paralle l with bulk and interfacial precipitation. This precipitation will be analysed and the role of oxygen will be evidenced.

\section{* UA 450}

* Heat Exchanger Method (HEM) is a registred trade mark of Crystal Systems Inc. Sa lem MA, USA 
Laser Beam Induced Current (LBIC) /6/ indicated that the minority carrier diffusion lengths were $<12 \mu \mathrm{m}$. These values correspond to a high density of electron recombination centers. These recombination centers come from localized states in the forbidden gap introduced by bulk defects and grain boundaries. The electrical activity of grain boundaries will be characterized by the LBIC mapping mode.

2 - EXPERIMENTAL METHODS

The aim of these experiments was to correlate electrical properties to the microstructure observed by Transmission Electron Microscopy (TEM). The experimental procedure had been developed previously /4,7/ and it was now adapted to the characteristics of the HEM material.

\subsection{Iransmission electron microscopy}

Conventional TEM and analytical Scanning Transmission Electron Microscopy (STEM) were used (microdiffraction, X-ray Energy Dispersive Spectroscopy (EDS) and Electron Energy Loss Spectroscopy (EELS)*) $/ 8 /$. At low $N_{A}$, small precipitates (50 $\AA$ ) could only be analysed by means of microdiffraction or moire fringes correlated with chemically characterized microstructures observed at higher Al concentration.

\subsection{Laser_Beam Induced_Current_mapeing (LBIC)}

MIS junctions for the minority carrier collection were realized on silicon surfaces which were successively polished, chemically etched and thermally oxidized. A $200 \AA$ aluminium layer was then deposited under ul tra high vacuum (5.10-9 torr). This typical thickness was chosen in order to limit the incident beam absorption. The LBIC mapping was obtained with a Ga As laser $(\lambda=0.844 \mu \mathrm{m})$ which has an absorption depth of $23 \mu \mathrm{m}$ and is thus insensitive to surface defects. A He Ne laser $(\lambda=0,633 \mu \mathrm{m})$ which has an absorption depth of $3.5 \mu \mathrm{m}$, was also used for comparison. The laser spot size was $20 \mu \mathrm{m}$, and the measuring step was $2.5 \mu \mathrm{m}$.

\section{3 - RESULTS}

\subsection{Micros tructure}

It has previously been shown that the poly-Si microstructure can be split into four zones which are related to $\mathrm{N}_{A}$. As a main result, $\left.A\right]$ segregation was evidenced at grain boundaries by X-ray EUS, specifically on extrinsic dislocations $/ 6 /$. For $\mathrm{N}_{\mathrm{Al}}<10^{19}$ at $\mathrm{cm}^{-3}$, dislocations are mostly situated at grain boundaries. The A1 concentration appears to be heterogeneous at a $0.1 \mathrm{~mm} \mathrm{scale.} \mathrm{For} \mathrm{instance} \mathrm{when} \mathrm{N}_{A 1}=$ $810^{19}$ at cm $\mathrm{cm}^{-3}$, local A1 concentration may reach $510^{20}$ at $\mathrm{cm}^{-3}$ in areas where the decorated dislocation density is found to be maximum. It can be noted that this local concentration ts lowered as the precipitates are enlarged, which is compatible with a preferred nucleation-on-dislocation process. At $N_{A} 1=10^{20}$ at cm-3, a decrease of the intra-grain defect density is observed in parallel wi th bulk and interfacial precipitation. These precipitates are single crystals as revealed by selected area electron diffraction (Fig. 1). They contain aluminium and oxygen as indicated by STEM EELS spectra (Fig. 2). These precipitates are found within grains as well as at boundaries, and their parameters correspond to $\gamma$-alumina. Indeed, their nucleation starts at $10^{18}$ at $\mathrm{cm}^{-3}$, which is much below the solubility limit $\left(210^{19}\right.$ at $\left.\mathrm{cm}^{-3}\right)$. At this concentration rate, they are observed preferentially at grain boundaries and in particular on (221) $\Sigma=9$ and (111) $\Sigma=3$ boundaries (fig.3).

\subsection{Electrical_activity}

LBIC mappings were drawn on two samples corresponding to $N_{A l}=1.610^{17}$ at $\mathrm{cm}^{-3}$ and $3.710^{17}$ at $\mathrm{cm}^{-3}$. First let us note that the mottled contrast which may be found on both samples - Fig. 4.a (large contrast) and fig. 5.a (fine contrast) - is due to

* JEOL $100 C X$ electron microscope wi th EDAX X-ray analyser ; VG HB5 electron microscope with Kevex X-ray analyser, Gatan energy loss spectrometer and Tracor digital treatment 


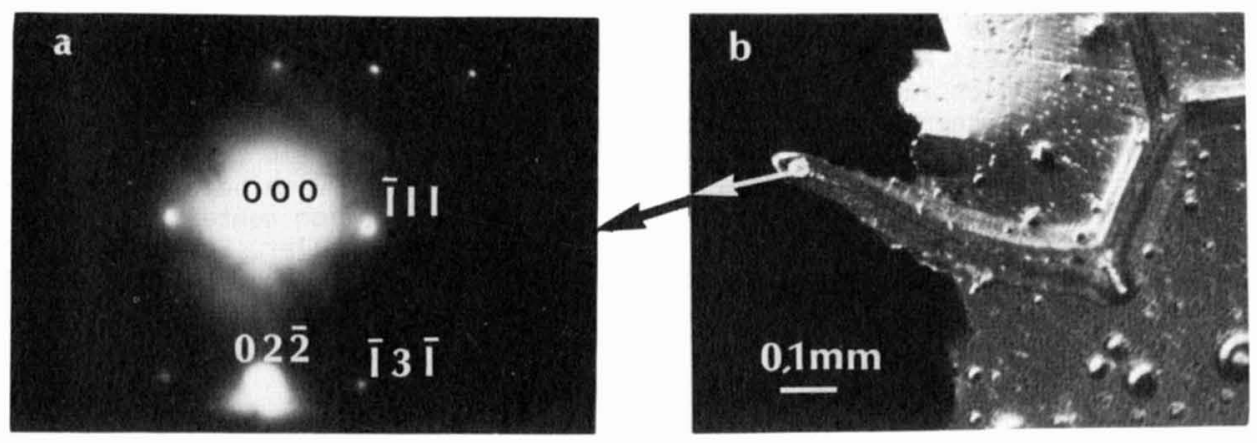

Fig. $1: \gamma-\mathrm{Al}_{2} \mathrm{O}_{3}$ single crystal precipitate

a) selected area diffraction, b) sample surface after ion milling
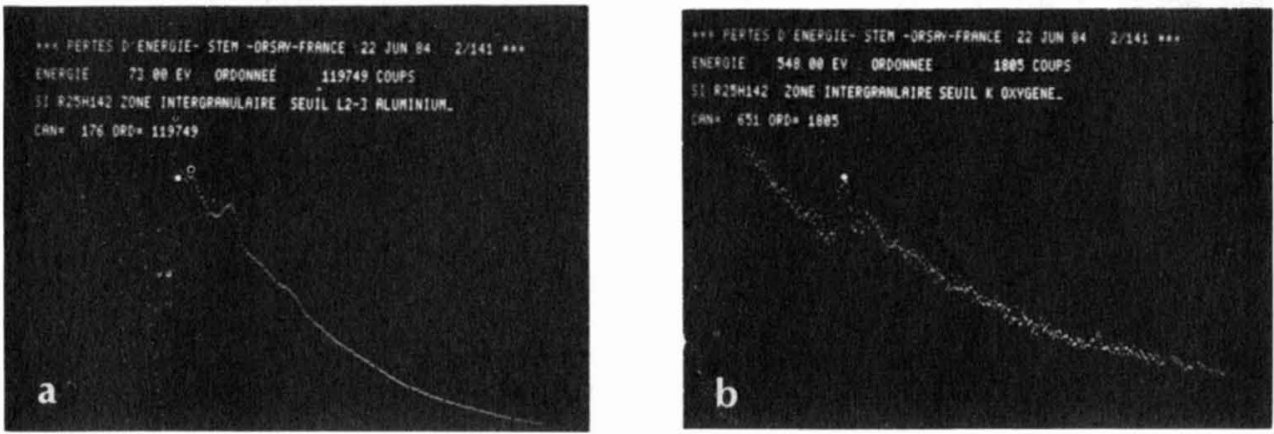

Fig. 2 : STEM Electron Energy Loss Spectra. Characterization of $A 1$ and 0 on a $\gamma-\mathrm{Al}_{2} \mathrm{O}_{3}$ precipitate.
a) A1 - $\mathrm{L}_{2}-3$ edge $(73 \mathrm{eV})$
b) 0 - $K$ edge $(532 \mathrm{eV})$
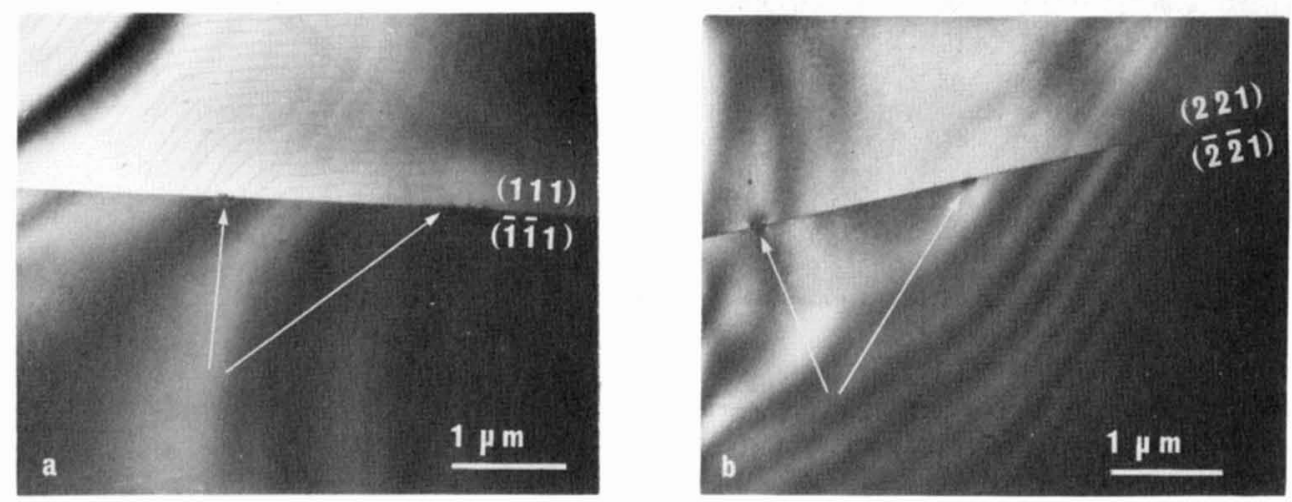

Fig. $3: \Sigma=3$ (a) and $\Sigma=9$ (b) twin boundaries with precipitates $\left(N_{A}\right)=1018$ at $\left.\mathrm{cm}^{-3}\right)$ 
chemical etching wich leads to an LBIC signal decrease with a He Ne Taser onty. In the sample with the lowest $A T$ concentration, we observe a limited variation of the induced current (variation ratio < 2 ). Fig. 4.b shows the LBIC mapping obtained for the area $4 . a$. It can be seen that the faceted $\Sigma>3$ twin boundary (B) onty, does show a high activity - i.e electron recombination-which reduces the LBIC signal. However it is to be noticed that small minima are observed in grain A with both lasers. Thus it can be inferred that they do correspond to bulk recombination centers. In the other sample, the photovoltaic signal within the grain is smaller. Furthermore, the intra-grain response is much more homogeneous as can be seen in fig. 5.b for grain $C$. It should be noted that this grain does not exhibit any twin whereas grain A (fig. 4) shows a high density of $\Sigma=3$ twins.
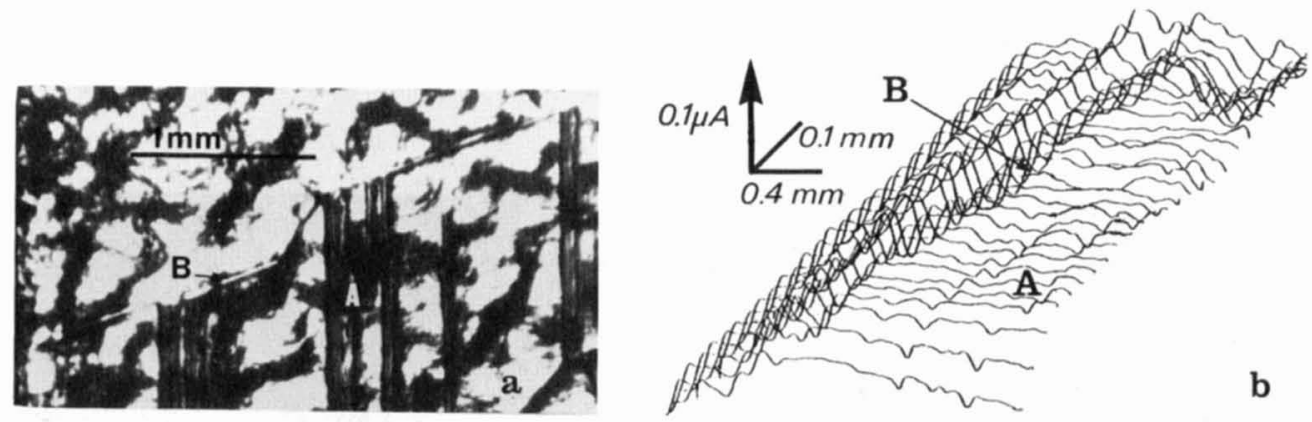

Fig. $4: \mathrm{N}_{\mathrm{A} 1}=1.610^{17}$ at $\mathrm{cm}^{-3}$

a) Optical micrography after chemical etching

b) LBIC signal obtained with a Ga As laser on the same area.
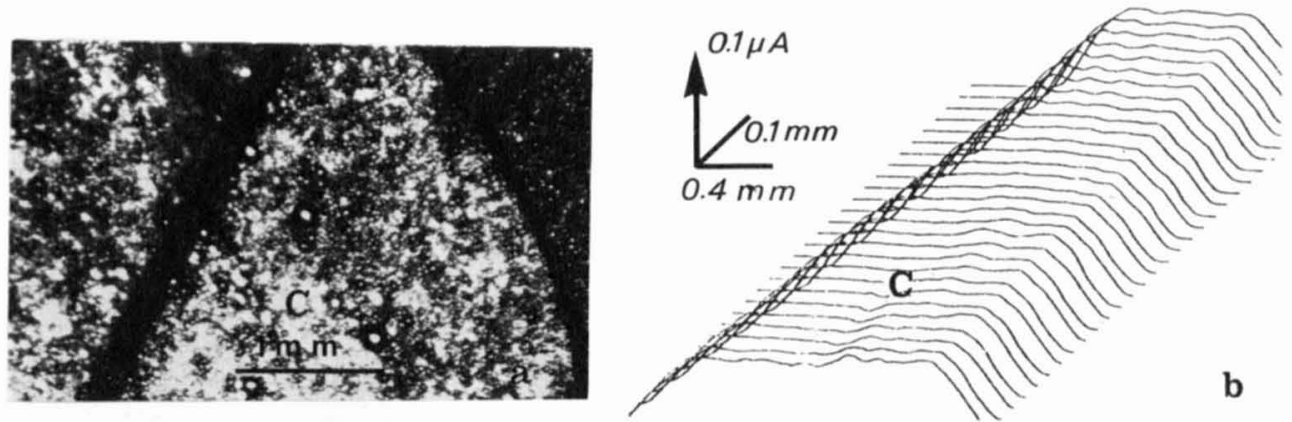

Fig. $5: \mathrm{N}_{\mathrm{A}}=3.710^{17}$ at $\mathrm{cm}^{-3}$

a) Optical micrography after chemical etching

b) LBIC signal obtained with a Ga As laser on the same area. 
4 - DISCUSSION

\subsection{Aluminium segregation}

Two main observations have to be considered : the existence of microprecipitation at grain boundary starting from $N_{A 1}=1018$ at $\mathrm{cm}^{-3}$, and the $A 1$ segregation on grain boundary extrinsic dislocations at $N_{A 1}=10^{19}$ at $\mathrm{cm}^{-3}$. Al precipitation is not expected below the solubility limit. However, this limit may be locally lowered by a co-segregation phenomenon with oxygen. Following the equilibrium reaction related to the solidification process $A 1$ can segregate at grain boundaries (A1 segregation coefficient in $S i: k \simeq 2 \cdot 10^{-3}$ ). The presence of AT extrinsic dislocations indicates that another segregation process occurs. This kinetic process is induced by a long distance stress field due to these dislocations. It can be assigned to a solid state relaxation mechanism which is very likely to occur during the slow cooling of the ingot. The fact, that nucleation is also observed on bulk dislocations and stacking fauits, backs up this mechanism. Moreover, the location of precipitates either in grains or in boundaries at higher $\mathrm{N}_{A 7}$, emphasizes the importance of dislocations as preferential sites for precipitation. Thus, it appears that solid state diffusion plays a greater role than the solid-liquid interface segregation.

\subsection{Electrical_activity of grain boundaries}

For $\mathrm{N}_{\mathrm{Al}}>10^{17}$ at $\mathrm{cm}^{-3}$, microresistivity measurements do not show any significant potential barriers - corresponding to the trapping of holes at grain boundaries - as may be expected from the low resistivity $<0.2 \Omega \mathrm{cm} / 6 /$. Thus it is very difficult to analyse local recombinations at interfaces, as simultaneous ly the bulk photoresponse gets very small due to the decrease in the minority carrier diffusion length. Finally the photoresponse may be blurred by preferential oxidation according to the grain orientation during the MIS diode processing.

LBIC mapping allows the differentiation between $\Sigma=3$ boundaries and other grain boundaries for the lowest $\left.N_{A}\right]\left(1.61017\right.$ at $\left.\mathrm{cm}^{-3}\right) . \Sigma=3$ boundaries are inactive when they are undecorated. Other grain boundaries are electrically active including twin boundaries with $\Sigma>3$. Furthermore, for $N_{A 1}<5.1017$ at $\mathrm{cm}^{-3}$, twin-free grains are not active. The activity of twinned grains, in this concentration range, is most likely related to the Al concentration heterogeneity (cf $\S 3.1$ ). This may lead to a local A1 amount > $10^{18}$ at $\mathrm{cm}^{-3}$ and to co-precipitation on extrinsic dislocations anchored on twin boundaries. The observed induced current modulation (which is less than proportional to NAi $-1 / 2 / 6,9 /)$ is compatible with this interpretation, and the photoresponse, obtained on grain A (fig. 4), might be a good example of such a mechanism.

\section{5 - CONCLUSION}

In HEM polysilicon, grains are mostly twin related and moreover, individual grains often contain a high density of microtwins. We have shown that microprecipitation occurs on extrinsic dislocations situated at twin boundaries and intra-grain microtwins for AT concentration $N_{A} 1>10^{18}$ at $\mathrm{cm}^{-3}$. This phenomenon is due to a co-segregation effect with oxygen as well as to microstructural heterogeneities. The main driving force for segregation is solid state relaxation. At $N_{A 1}=10^{20}$ at $\mathrm{cm}^{-3} \gamma$-alumina precipitates have been identified. It was found that $\Sigma=3$ twin boundaries are active - acting as recombinating loci - only if they contain precipitates. Other twin and grain boundaries are usually active. For $N_{A}<51017$ at $\mathrm{cm}^{-3}$ twinned grains only are active.

Since it has been shown /2/ that $A 1$ can also passivate grain boundaries it would be of prime importance to determine the electrical activity of grain boundaries on a finer scale. The precipitate-matrix interfaces and grain boundaries facets in particular deserve a careful analysis. For that purpose, we have started electron beam induced current measurements on thin samples by scanning transmission electron microscopy. This method should permit the determination of interfacial electrical activity with a spatial resolution $<100 \mathrm{~nm}$. 
The chemical behaviour of aluminium and oxygen plays an outstanding role on electrical properties as they can act either as free atoms or as complexes with vacancies $/ 10 /$. IR absorption measurements should bring new insights on the chemical environment of these elements. Finally the survey of thermally treated polysilicon would allow the distinction between recombination effects associated with intragrain defects and passivation mechanism at grain boundaries.

We are much grateful to G. Revel and J.L Pastol (CNRS Vitry) for the HEM polysilicon growth and to C. Colliex and P. Trebbia (Laboratoire de physique des Solides. Orsay) for the electron energy loss experiments.

\section{REFERENCES}

1. J.R. DAVIS, A. ROHATGI, G.H. HOPKINS, P.D. BLAIS, P. RAI-CHOUDHURI, J.R. MC CORMICK, H.C. MOLLENKOPF, I.E.E.E. Trans. E. D. 27, 677 (1980)

2. R. SUNDARESAN, D.E. BURK, J.G. FOSSUM, Proc. 16th I.E.E.E. Photovolt. Spec. conf. p. 421 (1980)

3. L.L. KAZMERSKI, J. Vac. Sci Technol. 20 (3), 423 (1982)

4. J.L. MAURICE, J.Y. LAVAL, J. Physique, supp1. au $n^{\circ} 10,43, \mathrm{C1}-207$ (1982)

5. G. REVEL, J.L. PASTOL, D. HANIA, H. NGUYEN DINH, Proc. 5 th EC Photovolt. Sol. En. Conf. , 1037 (1983)

6. J.L. MAURICE, J.L. PASTOL, J.E. BOUREE, J.Y. LAVAL, G. REVEL, M. RODOT, M.R.S. Conf. Strasbourg 1984, à paraître dans J. Physique (1984)

7. J.L. MAURICE, thèse de 3ème cycle, Paris (1982)

8. J.Y. LAVAL, M.C. AMAMRA, D. BROUSSAUD, W. MUSTEL, Revue de Chimie Minérale, 19, $690(1982)$

9. B.L. SOPORI, cited in Advances in Solar Energy. American Solar Energy Society T.1, 133 (1983)

10. N.B. URLI and B. PIVAC, Proc. 13th Int. Conf. on Defects in Semiconductors, Coronado Aug. 12-17, 1984. To be published in J. Electronic Materials (1984) 